Research Paper:

\title{
Early Hospitalization Reduces the Length-of-Hospital Stay and Antibiotic Use in Children With Moderate Diarrhea: A Study in Bangladesh
}

Md. Jahidul Hasan ${ }^{1^{*}}$ (D), Md. Suman ${ }^{2}$

1. Clinical Pharmacy Services, Department of Pharmacy, Dhaka, Bangladesh.

2. Matlab Health Research Centre, International Centre for Diarrhoeal Disease Research, Bangladesh (ICDDR,B), Dhaka, Bangladesh.

\begin{tabular}{|c|c|}
\hline $\begin{array}{l}\text { Use your device to scan } \\
\text { and read the article online }\end{array}$ & ditation Jahidul Hasan Md, Suman Md. Early Hospitalization Reduces the Length-of-hospital Stay and Antibiotic Use in Chil- \\
\hline aring & $\begin{array}{l}\text { dren With Moderate Diarrhea: A Study in Bangladesh. Journal of Pediatrics Review. 2021; 9(1):71-80. http://dx.doi.org/10.32598/ } \\
\text { jpr.9.1.916.1 }\end{array}$ \\
\hline a & doi http://dx.doi.org/10.32598/jpr.9.1.916.1 \\
\hline
\end{tabular}

\section{(i) $\$$}

Article info:

Received: 08 Jul 2020

First Revision: 25 Jul 2020

Accepted: 08 Nov 2020

Published: 01 Jan 2021
Keywords:

Diarrhea, Children,

Bangladesh,

Malnutrition, Antibiotic,

Adverse drug event

\section{A B ST R A C T}

Background: Childhood diarrheal diseases are common with mild-to-severe mortality rate worldwide. Lower-Middle-Income Countries (LMICS), including Bangladesh in South Asia, are still unable to save their under-5 lives due to diarrheal conditions.

Objectives: The main aim of this study was to evaluate the duration of hospital stay and use of antibiotics in under-2 children with moderate diarrhea in Bangladesh.

Methods: This study was done on hospitalized 6 months to 2 years old pediatric patients $(n=212)$ with an uncontrolled moderate type of diarrhea in 3 districts of Bangladesh. Based on the history of diarrhea onset, 133 and 79 patients were allocated in the Early Hospitalization (EH) and Delayed Hospitalization (DH) groups, respectively.

Results: To treat uncontrolled diarrhea at home, antibiotic therapy was initiated in $36.7 \%$ of patients in the $\mathrm{DH}$ group without any valid prescription, whereas only $7.5 \%$ of patients in the EH group received antibiotics $(\mathrm{P}<0.05)$. In the $\mathrm{DH}$ group, $67.1 \%$ of children received different antibiotic therapies for treating their diarrhea with or without other hospital-acquired infections during their extended hospital-stay period, resulting in Antibiotic-Associated Adverse Events (AAAEs) in $17.7 \%$ of the patients. At the same time, $21.1 \%$ of the patients in the $\mathrm{EH}$ group received antibiotics that caused AAAEs in $2.2 \%$ of them ( $P=0.001)$. The EH group, who received doctors' consultations and hospitalized within 2 days of the onset of diarrhea, stayed in the hospital for a maximum of 4 days. It was less than half a time that of the children in the $\mathrm{DH}$ group $(\mathrm{P}<0.05)$ (stayed for a maximum of 10 days), who visited doctors and admitted to hospitals at a later stage of diarrheal-onset.

Conclusions: Early doctor visits and hospitalization of under-2 children with uncontrolled moderate diarrhea may reduce the severity of the disease and risk of severe acute malnutrition, minimize the use of antibiotics with minimum chance of occurrence of adverse drug events, and cause early discharge from hospital. 


\section{Background}

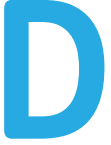

espite living in the second decade of the $21^{\text {st }}$ century with luminous pharmaceutical advancements, such as oral rehydration saline and zinc therapy, diarrhea is still the second leading cause of death in under-5 children worldwide (1-3). In Low-Middle-Income Countries (LMICs), including most countries in South Asia and Sub-Saharan Africa, diarrheal diseases are mainly responsible for the mild-tosevere rate of mortality and morbidity in children. In 2013, among the 6.3 million deaths of children globally before reaching their fifth year of life, diarrhea was accounted for 500000 deaths (4). In 2017, diarrhea was a leading cause of child death and accounted for $8 \%$ of total death of children worldwide (5). Centers for Disease Control and Prevention of the United States pointed out that diarrhea takes 2195 children's lives every day, and 801000 children every year. Also, diarrhea diseases are accused of 1 in every 9 child death before celebrating their fifth birthday $(3,4)$. As per the comment in Disability-Adjusted Life Years (DALYs), diarrhea is liable for $3.6 \%$ of the total global disease burden (6). If this child death-trend persists, 4.4 million children under the age of 5 will die by 2030, and diarrhea will be a leading cause for tracing this death-figure (4).

According to the statement of the United Nations Children's Fund (UNICEF), diarrhea mostly occurs among South Asian children less than 2 years of age, resulting in possible death (5). Basically, diarrhea is not a disease, but it is a symptom of other illnesses. Diarrhea is better defined as the presence of loose or watery stool, generally with increased frequency. Clinically, diarrhea is of three types: acute watery diarrhea lasting several hours to one week; acute bloody diarrhea; and persistent or chronic diarrhea for 14 days or longer (7). The severity of diarrhea depends on the frequency of loose or watery stool. So, the frequencies of more than 10 times, below 10 times, and a couple of times are called severe diarrhea, moderate diarrhea, and mild diarrhea, respectively (8). Acute diarrhea is caused by bacterial, viral, or parasitic infections and is resolved shortly with available remedies such as Oral Rehydration Salt Solution (ORSS) and zinc supplements. The World Health Organization (WHO) and meta-analyses of several randomized controlled trials recommended that Oral Rehydration Therapy (ORT), including hypo-osmolar oral rehydrating salts solutions and zinc supplements, are the primary treatment management in acute diarrhea (7, 9-11). However, acute diarrhea may produce moderate to severe complications, especially in younger children ( $<5$ years) (12). When acute diarrhea (less than 1 week) is not appropriately managed, it turns into Persistent Diarrhea (PD) (up to 14 days or more). At this stage, it becomes more complicated, requires hospitalization, and has a high rate of mortality, mostly in under-5 children (7).

Diarrhea (acute and persistent) is accountable for more than half of all children's deaths in the African and SouthEast Asian regions, including Bangladesh (an LMIC) (13, 14). Ninety percent and $60 \%$ of PD cases happen in children before their 6 months and below 1 year of age, respectively. This condition is a real threat to young children's lives in LMICs, mostly when it is not adequately managed at its acute stage (within the first 7 days of initiation) $(15,16)$. Children's death in Bangladesh is a national burning issue, and diarrhea is one of the leading causes of under- 5 children's death. Multiple Non-Governmental Organizations (NGOs), WHO, United Nations (UN), UNICEF, and the International Center for Diarrheal Disease Research, Bangladesh (ICDDR, B) and different agencies of the local government are closely working in Bangladesh to reduce the child death from diarrheal diseases. The high incidence of under- 5 children's death due to diarrhea mostly happen in rural areas of Bangladesh. The above-mentioned world's leading organizations, accompanied by the Bangladesh government, are trying to strengthen the system of diarrhea management from households without using too much of pharmaceutical products, including antibiotics (17).

\section{Study objectives}

The principal objective of this study was to evaluate the length-of-hospital stay and antibiotic use associated with the early versus delayed hospitalization of under- 2 children with moderate diarrhea in Bangladesh.

\section{Methods}

\section{Study design}

This 3-month-long prospective, observational study was conducted from August 2019 to October 2019 in multiple non-government hospitals of Dhaka, Cumilla, and Noakhali districts of Bangladesh. The study samples were children admitted to hospitals with moderate diarrhea. To collect the study patients' data, we contacted the parents of all children (patients). All patients' previous diseases, medication, and birth history were collected directly from the parents, and time-to-time medical history was collected from the corresponding medical centers. The progression of the patient's health status was recorded daily, and a continuous follow-up chart was maintained. 


\section{Study Samples}

The targeted samples of this study were 6 months to 2 years old patients $(n=212)$ with an uncontrolled moderate type of diarrhea (frequency of loose or watery stool below 10 times over 24 h) (8) started at home 48 hours to 5 days ago. Following the age-range and study criteria, 133 patients were taken as the Early Hospitalization (EH) group because they were admitted to hospitals to treat their uncontrolled high frequency loose or watery diarrhea that originated at home within the last 2 days. Seventy-nine patients of the same age group admitted to hospitals with similar characteristics of diarrhea initiated within the previous 5 days were considered as samples in the Delayed Hospitalization (DH) group. The weight and height of all patients were measured by using a digital body weight/height measurement scale (BY 90 baby scale, Beurer $\mathrm{GmbH}$, Germany) by a trained nurse during admission. Bodyweight was graded following the percentile range (underweight: <the $5^{\text {th }}$ percentile; healthy weight: between the $5^{\text {th }}$ and the $85^{\text {th }}$ percentile; overweight: Between the $85^{\text {th }}$ and the $95^{\text {th }}$ percentile; and obese: $\geq$ the $95^{\text {th }}$ percentile) (18). From hospital admission to hospital discharge, data of all the treatment managements, clinical progression, and clinical interventions in all patients were collected, systematically, and analyzed. All the patients' (both EH and $\mathrm{DH}$ groups) clinical outcomes, nutritional therapies, and antibiotic use data were evaluated group-wise and compared to each other accordingly.

\section{Inclusion and exclusion criteria}

The inclusion criteria of this study were patients ( 6 months to 2 years old) with a moderate type of diarrhea initiated 2 to 5 days before hospitalization; no hospitalization history for any disease over the last 1 month; no record of renal impairment, moderate to severe hepatic impairment and any gastrointestinal disorder; and full level of consciousness. Severe malnourished patients; those with known congenital disabilities; a history of chronic diarrhea; and patients with comorbidities, including cardiac anomalies, convulsion, and pneumonia, were excluded from this study.

\section{Statistical analysis and approval}

The obtained data were analyzed using IBM SPSS statistics v. 22 software. The results are expressed as Mean $\pm S D$ and percentages. The Pearson Chi-square test and the independent $t$ test were used for categorical and numerical variables, respectively. The Confidence Level (Cl) was $95 \%$. The statistical significance level was set at $\mathrm{P}<0.05$. Informed consent was obtained from the legal guardians (father/mother) of each patient (younger children) included in the study. The study protocol conforms to the ethical guidelines of the 1975 Declaration of Helsinki as reflected in a prior approval (1907SHOR014) by the Human Research Ethics Committee of Square Hospital, Dhaka, Bangladesh, on July 15, 2019.

\section{Results}

All patients of this study were of South Asian origin with a mean age of $12.3 \pm 5.3$ months and $12.3 \pm 5.5$ months in the early and delayed hospitalization group, respectively $(P=0.54)$ (Table 1$)$. The number of male patients in both $\mathrm{EH}(88, \mathrm{n}=133)$ and $\mathrm{DH}(51, \mathrm{n}=79)$ groups was higher than female patients (EH: 45; DH: 28) (statistically not significant) (Table 1). With low-birth-weight, $29.1 \%(23, \mathrm{n}=133)$ patients in the EH group and $40.4 \%(17, n=79)$ patients in the $\mathrm{DH}$ group born $(\mathrm{P}<0.05)$ (Table 1$)$. Among all children, $8.2 \%(11, n=133)$ and $7.5 \%(6, n=79)$ children in the $E H$ and $\mathrm{DH}$ groups, respectively, stopped getting their mother's breast-milk ( $P>0.05)$ before finishing their 2 years of age (Table 1). Ninety-one and 67 patients were with healthy body weight in the $\mathrm{EH}$ and $\mathrm{DH}$ groups, respectively; 36 and 8 patients were underweight in the $\mathrm{EH}$ and $\mathrm{DH}$ groups, respectively; and 6 and 4 children were found overweight during their hospital admission in the $\mathrm{EH}$ and $\mathrm{DH}$ groups, respectively (Table 1 ). No obese patient was found in the $\mathrm{EH}$ or $\mathrm{DH}$ group during hospitalization.

Previous medical histories, disease condition, past and current medication history, and birth history was taken by pediatric doctors from the parents of every patient in this study. A complete individual patient-wise evaluation note was generated before admitting the patient to the hospital. Before admitting to the hospital, the mean \pm SD number of 8-hourly stool frequency of the study patients was $1.85 \pm 0.8$ times and $3.2 \pm 0.4$ times in the $\mathrm{EH}$ and $\mathrm{DH}$ groups, respectively, and that was statistically significant. Thirty-nine percent of patients $(n=133)$ in the $\mathrm{EH}$ group were reported with electrolyte imbalance during their hospital admission, whereas $78.4 \%(n=79)$ of patients in the $\mathrm{DH}$ group had electrolyte imbalance, including hypokalemia $(P<0.05)$ (Table 1). The degree of dehydration (severe dehydration, some dehydration, and no dehydration) (9) was estimated in all study patients (assessed based on the presence of dry mouth symptoms, less frequent urination, lack of tear in crying, and body immobility) (7, 9) of both the groups during hospital admission with moderate diarrhea. Some dehydration (fluid deficit 50$100 \mathrm{~mL} / \mathrm{kg}$ of body weight) (11) was found at a higher rate $(45.5 \%)$ in the patients of the $\mathrm{DH}$ group than that 
Table 1. Baseline characteristics of the participants, clinical conditions, and adverse drug events

\begin{tabular}{|c|c|c|c|c|}
\hline \multirow{2}{*}{\multicolumn{2}{|c|}{ Characteristics }} & \multicolumn{2}{|c|}{ No. $(\%) /$ Mean \pm SD } & \multirow[b]{2}{*}{$\mathbf{P}$} \\
\hline & & $\begin{array}{c}\text { The EH Group } \\
(n=133)\end{array}$ & $\begin{array}{l}\text { The DH Group } \\
\quad(n=79)\end{array}$ & \\
\hline Ethnicity & South asian & $133(100)$ & $79(100)$ & - \\
\hline \multirow{3}{*}{ Age (months) } & Mean $\pm S D$ & $12.3 \pm 5.3$ & $12.3 \pm 5.5$ & \multirow{3}{*}{0.549} \\
\hline & & & & \\
\hline & Range (min-max) & $6-24$ & $6-24$ & \\
\hline \multirow{3}{*}{ Gender } & Male, No. & 88 & 51 & \multirow{3}{*}{0.412} \\
\hline & & & & \\
\hline & Female, No. & 45 & 28 & \\
\hline & History of low-birth-weight & $23(29.1)$ & $17(40.4)$ & 0.006 \\
\hline & Not feeding breast-milk & $11(8.2)$ & $6(7.5)$ & 0.861 \\
\hline \multirow{3}{*}{ Bodyweight status } & Underweight & 36 & 8 & \multirow{3}{*}{0.003} \\
\hline & Healthy weight & 91 & 67 & \\
\hline & Overweight & 6 & 4 & \\
\hline \multirow{7}{*}{ During admission } & Eight-hourly stool frequency & $1.85 \pm 0.8$ times & $3.2 \pm 0.4$ times & 0.001 \\
\hline & Electrolyte imbalance & $52(39.0)$ & $62(78.4)$ & 0.001 \\
\hline & Some dehydration & $55(41.3)$ & $36(45.5)$ & 0.549 \\
\hline & & & & \\
\hline & Fever (>100.4으) & $20(15.0)$ & $23(29.1)$ & 0.005 \\
\hline & Sign of malnutrition & $8(6.0)$ & $54(68.3)$ & 0.001 \\
\hline & Initiated AT before hospitalization & $10(7.5)$ & $29(36.7)$ & 0.001 \\
\hline & AAAE during hospital-stay & $3(2.2)$ & $14(17.7)$ & 0.001 \\
\hline
\end{tabular}

SD: Standard Deviation; AT: Antibiotic Therapy; AAADE: Antibiotic-Associated Adverse Event.

Journal of Pediatrics Review

in the EH group (41.3\%) (Table 1). Higher than normal body temperature (fever) was detected more in the $\mathrm{DH}$ group (29.1\%) than the patients of the $\mathrm{EH}$ group (15\%) $(\mathrm{P}<0.05)$. Children in the $\mathrm{EH}$ group had more than 10 time fewer signs of malnutrition (6\%) (including lack of appetite, tiredness, lack of concentration, and mental depression) than the $\mathrm{DH}$ group (68.3\%), and this was statistically significant (Table 1 ). Interestingly, $36.7 \%$ of patients in the $\mathrm{DH}$ group started antibiotic therapy to treat uncontrolled diarrhea without consulting with any doctor or having any valid prescription. However, when diarrhea was not controlled properly, they turned back to the hospital, finally. On the contrary, a significantly lower percentage of patients $(7.5 \%, n=133)$ in the $\mathrm{EH}$ group came under any antibiotic therapy before admitting to the hospital (Table 1). The use of antibiotics for the treatment of complicated diarrhea with or without other hospital-acquired infections in the children of the $\mathrm{DH}$ group resulting in a higher rate of Antibiotic-Associ- ated Adverse Events (AAAEs) (including hives, skin rash, itchy skin and eyes, angioneurotic edema, and mild respiratory distress) (17.7\%) during their extended duration of hospital-stay while the children of the EH group were less experienced with AAAEs (2.2\%) during their comparatively shorter period of hospital-stay $(P=0.001)$ (Table 1). The most common AAAEs were hives, itching, and restlessness (mild reactions), and no moderate or severe adverse event was recorded with antibiotics among the children of both groups taken antibiotics.

Most of the Under-2 children admitted in hospital with an uncontrolled moderate type of diarrhea with altered physical conditions received antibiotic therapy to treat diarrhea. Patients in the EH group came to the hospital and were hospitalized within 48 hours of the onset of diarrhea at home. During their stay in the hospital, $21.1 \%$ of the patients required different antibiotic therapies for their diarrhea treatment, whereas $67.1 \%$ of patients 
Early hospitalization group $(n=133)$

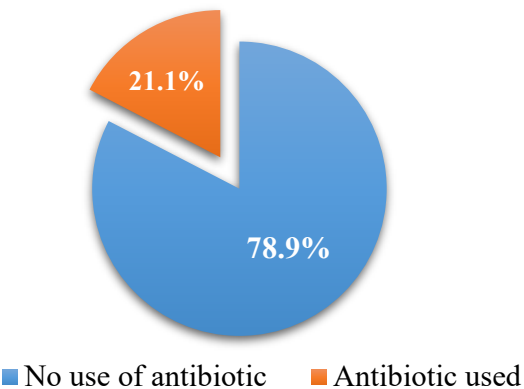

Figure 1. Use of antibiotics during hospitalization in the patients

in the $\mathrm{DH}$ group were undergone antibiotic therapies during their hospital stay $(\mathrm{P}=0.001)$. The main reasons behind this higher percentage of antibiotic use in the $\mathrm{DH}$ group were their deteriorated physical condition, the severity of diarrhea, and increased risk of comorbidities during their admission (Figure 1).

All patients of the EH group who were admitted early to hospital after the diarrheal event had a short period of hospital-stay. After getting admission to the hospital, they came under the anti-diarrheal treatment with or without the right antibiotic therapy, and the management of other symptoms started immediately. All patients of both groups received commercially available ORSS (ORSaline-N, Social Marketing Company, Bangladesh) and zinc supplement (Baby Zinc $20 \mathrm{mg}$ dispersible tablet, ACME, Bangladesh). Within a maximum of 4 days (average length-of-hospital stay was 1.5 days), diarrheal diseases of all patients of the EH group were treated successfully. They were discharged from hospitals,
Delayed hospitalization group $(\mathrm{n}=79)$

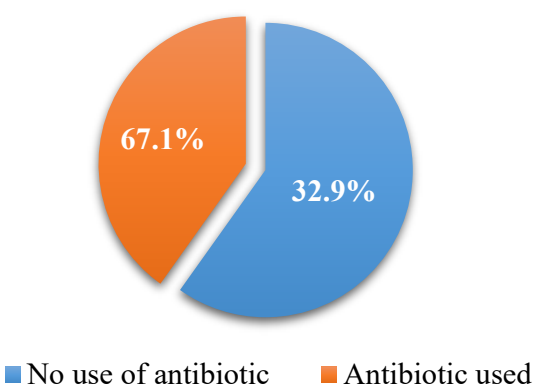

Journal of Pediatrics Review

whereas the $\mathrm{DH}$ group patients stayed at a maximum of 10 days (average length of hospital stay was 3.7 days) in hospitals to cure their complications completely. Then they were discharged to home $(\mathrm{P}<0.05)$ (Figure 2$)$.

\section{Discussion}

In this study, we compared the children who developed a moderate type of diarrhea at home and visited the nearest hospital within 48 hours of its initiation before deterioration of their physical condition (due to dehydration, electrolyte imbalance, and generalized weakness) with the children who came to the hospital with a lower health condition, one or more comorbidities, and life-risk associated with an uncontrolled moderate type of diarrhea. Here we found that the children of the $\mathrm{EH}$ group came to take doctors' consultation in the hospital during the early stage of moderate-diarrhea ultimately hospitalized for a shorter time (on average 1.5 days) compared to the children (the DH group) who were de-

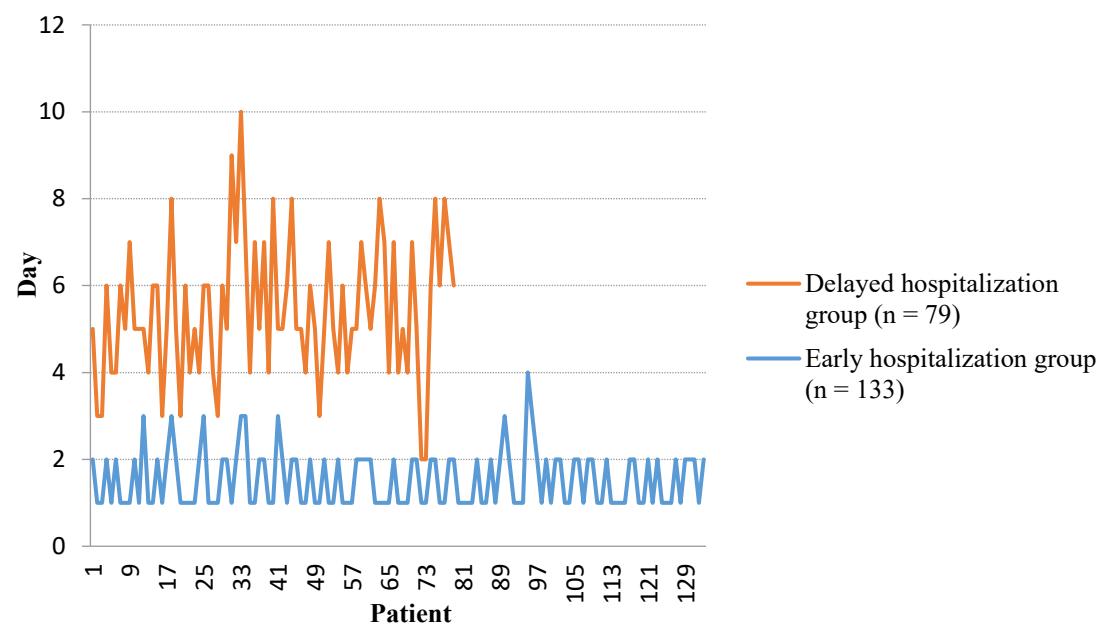

Figure 2. Length-of-hospital stay of the patients 
layed to come in hospital after a long-period (average hospitalization time was 3.7 days) of detecting diarrhea. By this time, they were treated with traditional homeremedies. The acute type of diarrhea that generally lasts for less than 7 days are prevalent in children under- 5 in LMICs, including Bangladesh. When the acute phase of diarrhea is not appropriately managed or turned into persistent diarrhea, it becomes more deadly for young children, so hospital admission is required (19). In Bangladesh, from 1989 to 2014, the child mortality rate has been reduced to $65 \%$, and the child death rate has been declined from 133 to 46 deaths per 1000 live births (20). With this improvement in the child death rate in Bangladesh, diarrhea is still a leading cause of under-5 children's death. So the proper control of diarrheal diseases in this age-group may improve the under- 5 child survival rate (19). A study demonstrated that $25 \%$ of children (aged between 1 to 4 years) deaths was accounted for PD, which was initiated as acute diarrhea and not appropriately managed at the early disease stage (16). This study found that early hospitalization of 6 months to 2 years old children, who were struggling with moderate diarrhea (at an early stage) at home, improved their disease condition shortly and significantly shortened their hospital stay duration.

Acute dehydration associated with frequent loose motion is a life-threatening event, especially in young children $(7,10,11)$. More than $40 \%$ of patients in both groups ( $\mathrm{EH}$ and $\mathrm{DH}$ ) of this study developed some dehydration following moderate diarrhea. For more than the last 30 years, oral rehydration salt solution (a blended clean watery solution of measured salt and sugar) has saved more than 50 million lives. That included children worldwide, especially from severe dehydration in diarrhea, and that is why The Lancet journal declared ORSS as the most important medical innovation of the 20th century (21). In the late 1960s, the United States and Bengali scientists of the International Centre for Diarrheal Disease Research, Bangladesh (ICDDR, B) developed ORSS. In the 1970s, the renowned Bangladeshi NGO, Bangladesh Rural Advancement Committee (BRAC), implemented a strategic plan to teach mothers to make ORSS at home by mixing Labon (salt) and Gur (sugar) in drinking water (22). However, due to the wrong measurement of ingredients and lack of understanding, the Ministry of Health and Family Welfare of Bangladesh is now discouraging the use of homemade ORSS and emphasizing the use of readymade packetized ORSS with zinc supplements available in most of the pharmacy shops, chain shops, and departmental stores at a lower price. In the absence of appropriate manage- ment of acute diarrhea, mostly with conventional home remedies, including ORSS during the early stage, children get weaker, the risk of further diarrhea-associated complications is increased, and when admitted to hospital at a later stage (with moderate diarrhea), the total length-of-hospital stay is extended (23). Despite feeding mothers' breast milk, under-2 children with recurring episodes of loose or watery diarrhea are at high risk of developing malabsorption with or without vomiting. Malnutrition is a vital cause for developing uncontrolled moderate diarrhea in younger children group, and this may subsequently lead to severe malnutrition, which may exacerbate the disease state (24). A recent study on LMICs' young children group demonstrated that persistent diarrhea was responsible for $32 \%$ to $62 \%$ of young children's death, which was initiated as acute diarrhea at home, where the treatment and attention to the disease progression were inadequate (16).

In low-middle-income countries, including Bangladesh, every under-3 child has experienced three episodes of diarrhea every year, and inadequate immunization, unsafe drinking water, improper sanitation system, and lack of hand-hygiene are the potential factors for developing frequent diarrheal diseases. Recent data from WHO showed that 780 million people are in a crisis of fresh drinking water, and 2.5 billion individuals have no proper sanitation facility worldwide. Sixty percent death from diarrhea is due to unsafe drinking water, and $40 \%$ risk of diarrheal diseases can be reduced with appropriate hand hygiene using soap (5). Children are very vulnerable to this unviable environment, and as a result, globally, around 1.7 billion diarrheal cases in under-5 children are reported every year (7). Bacteria, viruses, or parasites initially generate acute diarrhea and then spread rapidly from person-to-person through contaminated foods and water in an unhygienic environment. A rapid fluid loss in the form of frequent diarrhea in children may result in severe dehydration and electrolyte imbalance. Even during severe acute diarrhea, the total fluid loss (through diarrhea and vomiting) can be 3 times higher than the total circulating blood volume (80-125$250 \mathrm{~mL} / \mathrm{kg}$ of body weight/day) in a child (12).

At the time of moderate diarrhea, a treatment algorithm is highly needed to follow strictly. One of the oldest and very useful treatment algorithms is using an enormous amount of ORSS, vitamins, adequate mineral supplements (20 mg of elemental zinc), and appropriate use of antibiotics (25). In an under-2 child with moderate diarrhea, when this essential treatment algorithm is not appropriately performed at home, fluid loss increases excessively through diarrhea and vomiting, and 
malnutrition progresses rapidly. The clinical condition of the patient gets complicated, and it takes a long time to cure after hospitalization at this stage $(12,19,25)$. In our study, the delayed hospitalization group of children were admitted to hospitals with complicated health conditions and different comorbidities such as severe acute malnutrition and electrolyte imbalance. As a result, they required longer hospitalization time and more pharmacotherapies, including antibiotics, for their complete treatment in the hospital than the children of the early hospitalization group.

The use of antibiotics in under- 2 children with acute diarrhea without being adequately prescribed by a licensed physician is a controversial issue. Only bloody diarrhea is judiciously required antibiotics, but the high use of different antibiotics in diarrheal diseases in children is unclear (17). The study showed that in rural areas of Bangladesh, the rate of antibiotic use in male and female children was $31 \%$ and $36 \%$, respectively, which was very close to the national antibiotic consumption (23). In this study, $36.7 \%$ of children in the $\mathrm{DH}$ group received antibiotic therapies at home for their diarrheal management with other treatment algorithms. The basis and rationality of antibiotic usages were not known.

On the other hand, the EH group children received less antibiotic therapy (7.5\%) but reported to the hospital doctor at an earlier diarrhea stage. Multiple studies in Bangladesh found that in both rural and urban areas, antibiotics were used predominantly in acute diarrhea in under-5 children irrationally. In many cases, antibiotics are taken in diarrhea at home without having any prescription from a licensed physician. As a result, the risk of antibiotic resistance has increased among the children, and complete cure of diseases takes a longer time resulting in elevated hospital stay with increased treatment cost (26-29). The persisted diarrheal cases with late hospitalization results in more antibiotic use in children. A study found that in above 6 months old children, the use of antibiotics increased up to $79.38 \%$ for diarrheal treatment (19).

Moreover, overuse of antibiotics results in unwanted adverse drug events among children with diarrhea (30). A recent study showed that $42 \%$ of hospitalized pediatric patients developed antibiotic-associated adverse events, and these unwanted events complicated their overall treatment process during their hospital stay (31). In our study, children (the DH group) who came to the hospital at a later stage of uncontrolled moderate diarrhea received a higher percentage of antibiotic therapies $(67.1 \%)$ for treating their uncontrolled diarrhea and other nosocomial infections (during hospital stay), which corresponded to an increased rate of antibioticassociated adverse events (17.7\%). Whereas children in the $\mathrm{EH}$ group, who were reported to doctors of hospitals during the early stage of their moderate diarrhea, were managed with less antibiotic therapies $(21.1 \%)$ for the same purpose, which let them less experienced to antibiotic-induced unwanted events (2.2\%) during their hospital stay. Therefore, early hospitalization of children with moderate-to-severe diarrheal diseases (though staying on conventional home-remedies such as ORSS and zinc supplements) may result in short hospital-stay, less chance of acute diarrhea-associated rapid physical dilapidation, less chance of severe malnourishment, limited use of antibiotics for complete cure, and less possibility of experiencing adverse drug events during the period of hospitalization.

The significant limitations of this study were the small sample size of both groups, short duration of the study, lack of information about the etiology of diarrheal diseases, and limited information about the home-antibiotic use.

\section{Conclusions}

Acute diarrhea is a leading cause of child death worldwide. Children of LMICs are mostly living at a high risk of recurrent mild-to-severe diarrhea because of unsafe drinking water, improper sanitation, and lack of hand hygiene culture. Conventional home-remedies, including oral rehydration salt solution and zinc supplements, are primarily used to manage acute diarrhea at home. Still, this method sometimes fails to address diarrheal complications without having proper care and pharmacotherapies that are mostly available in hospital setups. This study found that in uncontrolled acute moderate diarrhea persisting over 48 hours in children ( 6 months to 2 years old), early hospitalization may be a practical solution. It results in a short hospital stay with less chance of further diarrhea-related complications, less risk of severe acute malnutrition, less requirement of antibiotic use for complication management, less scope of intending irrational antibiotic use at home, the limited possibility of antibiotic resistance, and minimum risk of antibiotic-associated adverse events during the hospital stay.

\section{Ethical Considerations}

\section{Compliance with ethical guidelines}

This study was conducted with the study-approval of the corresponding hospital authorities. Informed consent was obtained from the legal guardians (father/ 
mother) of each patient (younger children) included in the study. The study protocol conforms to the ethical guidelines of the 1975 Declaration of Helsinki as reflected in a prior approval (1907SH-OR014) by the Human Research Ethics Committee of Square Hospital, Dhaka, Bangladesh, on July 15, 2019.

Funding

This research received no specific grant from any funding agency in the public, commercial, or not-for-profit sectors.

\section{Authors' contributions}

Both authors equally contributed to preparing this article.

\section{Conflicts of interest}

The authors declared no conflicts of interest.

\section{Acknowledgements}

The authors of this study are very grateful to all hospital authorities for their permission to conduct this study and all kinds of cooperation.

\section{References}

1. Fischer Walker CL, Perin J, Aryee MJ, Boschi-Pinto C, Black $\mathrm{RE}$. Diarrhea incidence in low- and middle-income countries in 1990 and 2010: A systematic review. BMC Public Health. 2012; 12(1):220. [DOI:10.1186/1471-2458-12-220] [PMID] [PMCID]

2. Walker $\mathrm{CL}$, Black RE. Zinc for the treatment of diarrhoea: effect on diarrhoea morbidity, mortality and incidence of future episodes. International Journal of Epidemiology. 2010; 39 (Suppl 1):i63-9. [DOI:10.1093/ije/dyq023] [PMID] [PMCID]

3. Centers for disease control and prevention, U.S. department of health and human services. Global diarrhea burden, diarrhea: common illness, global killer. Global Water, Sanitation, \& Hygiene (WASH) [Internet]. 2015 [Cited: 2020 Dec 23]. Available from: https://www.cdc.gov/healthywater/ pdf/global/programs/Globaldiarrhea_ASIA_508c.pdf

4. GBD 2016 Diarrhoeal Disease Collaborators. Estimates of the global, regional, and national morbidity, mortality, and aetiologies of diarrhoea in 195 countries: a systematic analysis for the Global Burden of Disease Study 2016. The Lancet, Infectious Diseases. 2018; 18(11):1211-28. [DOI:10.1016/ S1473-3099(18)30362-1]
5. United Nations Children's Fund (UNICEF). Diarrhoeal disease [Internet]. 2019 [Cited: 2020 Jan 9]. Available from: https:// data.unicef.org/topic/child-health/diarrhoeal-disease/

6. Murray CJL, Vos T, Lozano R, Naghavi M, Flaxman AD, Michaud C, et al. Disability-Adjusted Life Years (DALYs) for 291 diseases and injuries in 21 regions, 1990-2010: a systematic analysis for the Global Burden of Disease study 2010. Lancet. 2012 380(9859):2197-223. [DOI:10.1016/S0140-6736(12)61689-4]

7. World Health Organization (WHO). Diarrhoeal disease. Newsroom [Internet]. 2017 [Cited: 2020 Jan 9]. Available from: https://www.who.int/news-room/fact-sheets/detail/diarrhoealdisease

8. Michigan Medicine, University of Michigan. Mild, moderate, or severe diarrhea. Health library [Internet]. 2018 [Cited: 2020 Jan 23]. Available from: https://www.uofmhealth.org/healthlibrary/sig18272

9. Wessells KR, Brown KH, Kounnavong S, Barffour MA, Hinnouho GM, Sayasone $S$, et al. Comparison of two forms of daily preventive zinc supplementation versus therapeutic zinc supplementation for diarrhea on young children's physical growth and risk of infection: study design and rationale for a randomized controlled trial. BMC Nutrition. 2018; 4:39. [DOI:10.1186/s40795-018-0247-6] [PMID] [PMCID]

10. Bhutta ZA, Bird SM, Black RE, Brown KH, Gardner JM, Hidayat $A$, et al. Therapeutic effects of oral zinc in acute and persistent diarrhoea in children in developing countries: Pooled analysis of randomized controlled trials. The American Journal of Clinical Nutrition. 2000; 72(6):1516-22. [DOI:10.1093/ ajcn/72.6.1516] [PMID]

11. Lazzerini M, Ronfani L. Oral zinc for treating diarrhoea in children. Cochrane Database of Systematic Reviews. 2012 (6):CD005436. [DOI:10.1002/14651858.CD005436.pub3]

12. Koletzko S, Osterrieder S. Acute infectious diarrhea in children. Archive of "Deutsches Ärzteblatt International. 2009; 106(33):539-47. [DOI:10.3238/arztebl.2009.0539] [PMID] [PMCID]

13. Bhutta ZA, Das JK, Walker N, Rizvi A, Campbell H, Rudan I, et al. Lancet Diarrhoea and pneumonia interventions study group. Interventions to address deaths from childhood pneumonia and diarrhoea equitably: What works and at what cost? Lancet. 2013; 381(9875):1417-29. [DOI:10.1016/S01406736(13)60648-0]

14. Liu L, Johnson HL, Cousens S, Perin J, Scott S, Lawn JE, et al. Child health epidemiology reference group of WHO and UNICEF. Global, regional, and national causes of child mortality: An updated systematic analysis for 2010 with time trends since 2000. Lancet. 2012; 379(9832):2151-61. [DOI:10.1016/ S0140-6736(12)60560-1]

15. Mathai J, Raju B, Bavdekar A. Pediatric Gastroenterology Chapter, Indian Academy of Pediatrics. Chronic and persistent diarrhoea in infants and young children: Status statement. Indian Pediatr Indian Pediatr. 2011; 48(1):37-42. [DOI:10.1007/ s13312-011-0018-9] [PMID] 
16. Rahman AE, Moinuddin M, Molla M, Worku A, Hurt L, Kirkwood B, et al. Childhood diarrhoeal deaths in seven low- and middle-income countries. Bull World Health Organ. 2014; 92(9):664-71. [DOI:10.2471/BLT.13.134809] [PMID] [PMCID]

17. Rahman AS, Islam MR, Koehlmoos TP, Raihan MJ, Hasan MM, Ahmed T, et al. Impact of NGO training and support intervention on diarrhoea management practices in a rural community of Bangladesh: An uncontrolled, single-arm trial. PLoS One. 2014; 9(11):e112308. [DOI:10.1371/journal.pone.0112308] [PMID] [PMCID]

18. Centers for Disease Control and Prevention. National Center for Health Statistics: Clinical Growth Charts. National center for health statistics [Internet]. 2017 [Cited: 2020 Jan 25]. Available from: https://www.cdc.gov/growthcharts/clinical_charts.htm

19. Mahfuz M, Alam MA, Islam SB, Naila NN, Chisti MJ, Alam NH, et al. Treatment outcome of children with persistent Diarrhoea admitted to an Urban Hospital, Dhaka during 20122013. BMC Pediatr. 2017; 17(1):142. [DOI:10.1186/s12887017-0896-7] [PMID] [PMCID]

20. NIPORT Mitra andAssociates and ICF. Bangladesh demographic and health survey 2014 (policy brief). Technical report, National Institute of Population Research and Training (NIPORT), Mitra and Associates, and ICF International [Internet]. 2016 [Cited: 2020 Jan 25]. Available from: https://www. aidsdatahub.org/sites/default/files/publication/DHS_Bangladesh_2014.pdf

21. Yee A. A simple solution: The history of ORS in Bangladesh. GlobalPost, Public Radio International [Internet]. 2013 [Cited: 2020 Jan 25]. Available from: https://www.pri.org/stories/2013-06-25/simple-solution-history-ors-bangladesh

22. University of Washington Global Health START Program, Request from Bill \& Melinda Gates Foundation. Bangladesh ORS case study. ORS-Zinc, START Program [Intenet]. 2014 [Cited: 2020 Jan 26]. Available from: https://www.shopsplusproject. org/sites/default/files/resources/Bangladesh\%200RS\%20 Case\%20Study.pdf

23. Larson CP, Saha UR, Islam R, Roy N. Childhood diarrhoea management practices in Bangladesh: Private sector dominance and continued inequities in care. International Journal of Epidemiology. 2006; 35(6):1430-9. [DOI:10.1093/ije/dyl167] [PMID]

24. Guerrant RL, Oriá RB, Moore SR, Oriá MO, Lima AA. Malnutrition as an enteric infectious disease with long-term effects on child development. Nutrition Reviews. 2008; 66(9):487-505. [DOI:10.1111/j.1753-4887.2008.00082.x] [PMID] [PMCID]

25. Ashraf H, Bhan MK, Bhatnagar S, Bhutta Z, Brown KH, Dung PT, et al. Evaluation of an algorithm for the treatment of persistent diarrhoea: A multicentre study. Bull World Health Organ. 1996; 74(5):479-89. http://dspace.icddrb.org/jspui/ handle/123456789/2009

26. Raghu MB, Balasubramanian S, Balasubrahmanyam G, Indumathy, Ramnath A. Drug therapy of acute diarrhea in children - actual practice and recommendations. The Indian Journal of Pediatrics. 1995; 62(4):433-7. [DOI:10.1007/BF02755063] [PMID]

27. Nizami SQ, Khan IA, Bhutta ZA. Drug prescribing practices of general practioners and paediatricians for childhood diarrhea in Karachi, Pakistan. Social Science \& Medicine. 1996; 42(8):1133-9. [DOI:10.1016/0277-9536(95)00386-X]

28. Alam MB, Ahmed FU, Rahman ME. Misuse of drugs in acute diarrhea in under-five children. Bangladesh Medical Research Council Bulletin. 1998; 24(2):27-31. [PMID]

29. Chowdhury AK, Matin MA, Islam MA, Khan OF. Prescribing pattern in acute diarrhea in three districts in Bangladesh. Tropical Doctor. 1993; 23(4):165-6. [DOI:10.1177/0049475 59302300408] [PMID]

30. Bruzzese E, Giannattasio A, Guarino A. Antibiotic treatment of acute gastroenteritis in children. F1000Research. 2018; 7:193. [DOI:10.12688/f1000research.12328.1] [PMID] [PMCID]

31. Murphy JL, Fenn N, Pyle L, Heizer H, Hughes S, Nomura $\mathrm{Y}$, et al. Adverse Events in Pediatric Patients Receiving Longterm Oral and Intravenous Antibiotics. Hospital Pediatrics. 2016; 6(6):330-8. [DOI:10.1542/hpeds.2015-0069] [PMID] 
This Page Intentionally Left Blank 